\title{
Enfermeiros e a família do portador de transtorno mental
}

\author{
Nurses and the family of the patient with mental disorder \\ Enfermeros y la familia del paciente con trastorno mental
}

\section{Vania Moreno'}

'Universidade Estadual Paulista Júlio de Mesquita Filho. Faculdade de Medicina de Botucatu. Escola de Enfermagem. Botucatu, SP

Submissão: 14/05/2009

Aprovação: $09 / 07 / 2010$

\section{RESUMO}

É um estudo de natureza Qualitativa, Que teve por objetivo conhecer como os enfermeiros que atuam em saúde mental obtiveram conhecimentos sobre a família durante sua formação acadêmica, visualizam a mesma em sua prática cotidiana e como deveria ser a formação profissional considerando a família no cenário da assistência. Utilizou-se como instrumento de coleta de dados a entrevista semiestruturada. Foram entrevistados seis enfermeiros. A análise dados permitiu construir três categorias temáticas: A formação acadêmica e profissional - a ausência da temática família; a visão dos enfermeiros sobre a família do portador de sofrimento psíquico e um novo olhar sobre a família - o papel do ensino. Os enfermeiros obtiveram poucos conhecimentos durante a graduação sobre a temática família; no cotidiano institucional, valorizam a família como participante do cuidado e indicam que a necessidade do conteúdo sobre família esteja alicerçada no caráter interdisciplinar.

Descritores: Enfermagem; Família; Serviços de saúde mental.

\section{ABSTRACT}

This Qualitative study aimed at investigating how mental health nurses acquired knowledge about the theme family during their academic training, how they see families in their daily practice, and how should professional training be considering the presence of the family in the care setting. Data were collected using semistructured Questionnaires. Six nurses were interviewed. Data analysis allowed the establishment of three theme categories: Academic and professional training - absence of the family theme; the nurses' perception of the family with a mentally ill member; and a new vision of the family - the role of teaching. During undergraduate education, nurses aceuired little knowledge about the theme family; in the institutional routine, they praise the family as a participant of care; and indicate that the need for knowledge about families is based on the interdisciplinary character of education.

Key words: Nursing; Family; Mental health services.

\section{RESUMEN}

Este es un estudio de naturaleza cualitativa, Que tuvo por objetivo descubrir cómo los enfermeros Que actúan en salud mental obtuvieron conocimientos sobre la familia durante su formación académica, cómo la ven en su práctica cotidiana y cómo debería ser la formación profesional considerando a la familia en el escenario de la asistencia. Se utilizó como instrumento de compilación de datos la entrevista semiestructurada. Se entrevistó a seis enfermeros. El análisis de los datos permitió construir tres categorías temáticas: La formación académica y profesional - la ausencia de la temática familia; la visión de los enfermeros sobre la familia del portador de sufrimiento psíQuico y una nueva mirada sobre la familia - el papel de la enseñanza. Los enfermeros recibieron pocos conocimientos durante la graduación sobre el tema familia; en el cotidiano institucional valoran a la familia como participante del cuidado y afirman Que la necesidad del contenido sobre familia está basado en el carácter interdisciplinario.

Descriptores: Enfermería; Familia; Servicios de salud mental.

\section{AUTOR CORRESPONDENTE Vania Moreno. Distrito de Rubião Júnior. CEP I 86 I8-000. Botucatu, SP.}

E-mail: btmoreno@terra.com.br 


\section{INTRODUÇÃO}

A família tem sido convidada a compor os vários cenários de atenção à saúde e a participar ativamente no processo do cuidado ao portador de transtorno mental. É fato decorrente dos pressupostos da reforma psiQuiátrica Que busca a inclusão do portador na família e sua reintegração no meio social.

A família deve estar inserida nos serviços de saúde, e preconizada sua presença desde a Constituição Que a considera a base da sociedade, devendo receber, portanto, especial proteção do Estado $^{(1)}$.

A legislação em saúde mental desde a primeira portaria, a 224/ 92, Que norteava os serviços de saúde mental indicava o atendimento do familiar como uma das atividades a serem desenvolvidas pelos profissionais. A portaria 336/2002 Que regulamenta os centros de atenção psicossocial (CAPS) relaciona o atendimento à família entre as ações a serem executadas pela equipe técnica, e a Portaria 25 1/2002 Que estabelece diretrizes e normas para assistência em hospital psieuiátrico, inclui programas específicos e interdisciplinares visando ao tratamento de acordo com a necessidade de cada usuário e de sua família ${ }^{(2)}$.

A família é entendida como um espaço privilegiado onde aprendemos a ser e a conviver, independente de formas ou modelos Que possamos assumir. Ela é a matriz de identidade individual e articula gêneros. Faz a mediação entre o público e o privado e está imersa em valores culturais Que são transmitidos entre gerações, possuem suas crenças Que permeiam as relações interpessoais ${ }^{(3-4)}$.

A família é compreendida como um sujeito Que se comporta de forma estratégica, realizando avaliação e escolhas frente a um conjunto de recursos disponíveis em uma perspectiva temporal(5).

Nos serviços de saúde, a família pode ser visualizada como auxiliar de processos diagnósticos e de tratamentos individuais ou então é avaliada como um problema Que deve ser transformado em objeto terapêutico ${ }^{(3,6)}$.

A família do portador de sofrimento psíquico deveria ser incentivada a participar efetivamente do cenário sociocultural, por estar inserida em espaços Que trazem a discussão da reforma psieuiátrica com o objetivo de provocar o imaginário social para refletir sobre a loucura, a doença mental, o hospital psiQuiátrico, tomando-se como ponto de partida a produção cultural e artística dos sujeitos envolvidos, cuja contribuição busca desmistificar o preconceito do "doente mental perigoso e incapaz"(7).

A família foi banida da assistência na constituição da psieuiatria enquanto ciência Que se pautava no paradigma cartesiano e, no ensino, ela não foi inserida nos conteúdos escolares, pois a formação em saúde se baseou em disciplinas. Na assistência ou ensino, utilizou-se o reducionismo cartesiano como forma de obter-se uma explicação sobre os fenômenos de forma simplificada ${ }^{(8)}$.

No momento atual, busca-se devolver a complexidade do objeto, através da interdisciplinaridade Que é um princípio mediador entre as disciplinas Que aponta para a insuficiência de diversos saberes nos campos disciplinares, permite uma convivência criativa com as diferenças e legitima a negociação de sujeitos concretos, conceitos e métodos entre as diferentes áreas do conhecimento ${ }^{(9)}$.

O trabalho interdisciplinar busca soluções compartilhadas para atender os problemas das pessoas e das instituições através da possibilidade de atividades conjuntas onde se respeitam as bases disciplinares específicas de cada profissão ${ }^{(10)}$.

Atender a família em saúde mental implica construir nos serviços de saúde mental uma prática interdisciplinar, através da troca efetiva entre disciplinas e profissionais na tentativa de estabelecer a colaboração entre sujeitos com o objetivo de melhorar a vida das famílias dos portadores de sofrimento mental.

Esta investigação buscou apreender como os enfermeiros Que atuam nos serviços de saúde mental obtiveram conhecimentos sobre a família durante a sua formação acadêmica; como visualizam a família em sua prática cotidiana e como deveria ser a formação do novo profissional Quando inserida a família no cenário da assistência.

\section{MÉTODO}

Optou-se por estudo exploratório descritivo de natureza Qualitativa por entender Que a compreensão de um processo ocorre mediante o Que as pessoas constroem como significado de suas ações, atitudes e crenças e descrevem em Que consistem estes mesmos significados $^{(1)}$.

Para a coleta de dados, utilizou-se uma entrevista semiestruturada, com as seguintes Questões norteadoras: Conhecimentos adeuiridos sobre a família durante sua formação acadêmica e pósgraduação, o papel da família no cuidado ao portador de sofrimento psíquico, facilidades e dificuldades na interação com as famílias. Também ações de enfermagem desenvolvidas junto à família, contribuição na formação do novo profissional enfocando a família e, ainda, se buscaram os dados pessoais e situação profissional: idade, sexo, a instituição Que trabalha e o tempo, formação profissional: escola em Que se formou e o tempo de formado e, cursos de pós-graduação.

As entrevistas foram realizadas após a aprovação do projeto pelo Comitê de Ética em Pesquisa da Faculdade de Medicina de Botucatu - Unesp, em parecer ofício 368/2001. Os entrevistados foram informados a respeito da pesquisa para então consentir em participar do mesmo.

Foram entrevistados seis enfermeiros dentre os Quais três trabalhavam em um hospital psiQuiátrico público em unidade de tratamento de pacientes agudos, duas trabalhavam em um centro de atenção psicossocial e uma trabalhava em hospital dia de um hospital de ensino. Buscou-se conhecer a totalidade dos enfermeiros Que atuavam frente a portadores de transtorno mental na fase aguda de adoecimento.

Para análise dos dados, foi utilizada a análise temática Que é uma vertente da analise de conteúdo ${ }^{(12)}$. Inicialmente foram realizadas leituras sucessivas do material coletado. Em um segundo momento, os achados foram ordenados visando organizar as respostas através das diferenças e semelhanças para permitir o agrupamento de idéias que se constituiu como categorias temáticas. Estas categorias foram articuladas e relacionadas com os dados existentes na literatura ${ }^{(12)}$.

\section{RESULTADOS E DISCUSSÃO}

Dentre os entrevistados, todos são mulheres, com faixa etária entre 23 a 46 anos; o tempo de formado varia de 10 a um ano e sete meses, sendo Que dois enfermeiros cursaram a graduação em escolas particulares e apenas dois não possuem especialização na 
área de Enfermagem Psiquiátrica. O tempo de trabalho em saúde mental ou psiQuiatria variou de Quatro meses a nove anos. Nesta investigação, não discriminamos o local de trabalho como forma de garantir o anonimato nas falas dos entrevistados.

A análise temática permitiu construir as seguintes categorias: A formação acadêmica e profissional - a ausência da temática família; a visão dos enfermeiros sobre a família do portador de sofrimento psíquico e um novo olhar sobre a família - o papel do ensino, Que apresentaremos a seguir.

\section{A formação acadêmica e profissional - a ausência da temática família.}

Com relação aos conhecimentos adQuiridos sobre a família durante o Curso de Graduação em Enfermagem, os entrevistados relatam:

Na época Que eu fazia faculdade eu não me lembro [...] de prática de conhecimento incluindo a família, acho Que a gente se preocupava mais com o paciente [...]. Não incluindo a família. (E3)

[...] a família era para buscar a história e saber como o paciente se comporta em casa como é Que, Que ela cuida, nada muito elaborado. Eram coisas práticas de utilização da instituição mesmo, para fins de diagnóstico. (E4)

[....] agora com relação às matérias curriculares mesmo, muito pouco eu ouvi falar da família [...]. Ficou bem escasso. (E I)

Os entrevistados concluíram o curso de graduação em Enfermagem por diversas faculdades, tanto particulares como públicas. Porém todos os enfermeiros apontam para a insuficiência Que a temática da família foi abordada durante o curso de graduação. Em nenhuma disciplina priorizou-se o conteúdo sobre família.

A família era visualizada como auxiliar nos processos diagnósticos através das informações Que forneciam aos alunos ${ }^{(3,6)}$

Os currículos de enfermagem tiveram um "olhar" voltado para o ensino das especialidades atendendo a política vigente no país. O modelo preconizado era o biomédico tendo como enfoque os aspectos centrados no hospital, a busca da cura da doença enQuanto terapêutica e o tratamento descontextualizado da vida do paciente ${ }^{(13)}$.

Os enfermeiros que cursaram Especialização em Enfermagem psiQuiátrica referem os conhecimentos adQuiridos:

O curso de especialização abriu as portas para a família, para a gente ter contato e tirar o fantasma de Que a família era uma coisa muito complicada, abriu o interesse da gente. (E2)

Na especialização, onde a gente começa a ver Que para você começar a trabalhar, para conhecer melhor o cliente, o paciente Que está sob seus cuidados, é interessante você incluir a família, nesse cuidado. (E4)

Os enfermeiros colocam Que a partir do curso de especialização houve uma mudança no "olhar" a família. Esta é visualizada como aliada no tratamento, permitindo Que o profissional comece a percebê-la como parte integrante de um projeto a ser construído contando com a sua participação.

O curso de especialização em enfermagem psiQuiátrica constitui um processo Que visa ampliar os conhecimentos da área, preparando os profissionais para transformar a prática ${ }^{(14)}$. Espera-se Que os enfermeiros especialistas busquem construir uma nova forma de atender as famílias nos cenários em Que estão atuando.

\section{A visão dos enfermeiros sobre a família do portador de sofrimento psíquico}

Nos depoimentos, os enfermeiros falam sobre a importância da família no tratamento:

[....] o paciente não é o único, ele pertence a uma família, a história de vida dele é importante para a gente entender o que está se passando, para a gente planejar o cuidado, até entender hábitos, o dia a dia [...] com Quem ele vive [...]. (E6)

[...] é entender que ela (família) também tem demandas e sofrimentos [...]. Às vezes o hospital cuida do paciente e culpabiliza a família ou fica do lado dela e culpa o paciente. E as famílias nos grupos falaram Que se sentiram abandonadas pelo serviço e eu acho Que a família precisa ser cuidada também. (E2)

Eu acho Que se o adoecer tem implicação também no contexto familiar, você vai ter Que escutar o familiar e ver Qual o entendimento que ele tem do problema, Quais os recursos que tem no enfrentamento. (E4)

Os enfermeiros percebem a importância da família no projeto terapêutico do portador de transtorno mental e relatam Que encontram dificuldade no relacionamento de famílias de pacientes em condição crônica de vida:

A dificuldade maior é o desgaste Que ela já vem sofrendo todos os anos com o paciente [...], ele já internou uma cinQuenta vezes, [...] ele voltou, reinternou, tem muita essa distância do familiar porQue o paciente já internou muitas vezes. (E I)

[.... principalmente Quando a família não foi trabalhada, pacientes crônicos, de uma evolução crônica, estigmatizados, Que perderam o valor dentro da família, Que reproduziu o sentimento de não dar certo, [...] estão cristalizadas. (E4)

O enfermeiro constata Que a família precisa estar inserida nos projetos terapêuticos singulares dos portadores de sofrimento psíeuico como forma de garantir o tratamento no CAPS:

[...] a maioria dos casos que a gente vê lá no CAPS onde você deixou a família do lado, são casos Que não deram certo, enquanto o paciente tiver nessa rede familiar, você tem Que valorizar e tentar cuidar mesmo dessa família. (E4)

Os enfermeiros relatam Que as famílias se sentem desgastadas decorrentes das várias internações dos pacientes no hospital psieuiátrico e indicam que os familiares de portadores de evolução crônica são menos receptivas às novas propostas de tratamento ${ }^{(15-16)}$.

Os serviços substitutivos precisam trabalhar com a resistência 
dos familiares de portadores de transtorno mental em condição crônica de vida, fato decorrente da ausência de dispositivos institucionais durante décadas e que contavam como único recurso a internação psiQuiátrica.

A família deve ser estimulada a modificar sua forma de visualizar e cuidar do portador de transtorno mental, visando melhorar a convivência e permitir sua inserção no meio familiar. Os serviços de saúde mental têm um papel importante, devendo proporcionar à família espaços de trocas, possibilitando Que sejam parceiros em uma nova forma de cuidado.

Os entrevistados referem Que não realizam ações de enfermagem sistemáticas voltadas para as necessidades das famílias Que são assistidas nos serviços. As atividades são esporádicas, de acordo com a carência e consistem basicamente no hospital psiQuiátrico em orientação sobre internação ou alta, uso de medicação e nos serviços substitutivos à realização de visitas domiciliares. Trata-se de atividades inerentes ao papel do enfermeiro Que contribuem para o trabalho em equipe.

A família se insere dentro de um contexto interdisciplinar Que transcende o papel de um único profissional; deve-se favorecer a negociação entre os sujeitos envolvidos no processo terapêutico, portador, familiares e profissionais do serviço com o objetivo de conhecer e intervir nos problemas advindos da convivência com o sofrimento psíquico nos diversos cenários: casa, serviço de saúde e comunidade ${ }^{(9-10)}$.

\section{Um novo olhar sobre a família - o papel do ensino.}

As enfermeiras Que estão na prática apontam para a necessidade de incluir a família no plano de cuidados:

Porque é difícil, mas a gente sabe da importância, convencendo o familiar a participar do tratamento e uma coisa que a gente deveria aprender também na graduação, como cuidar dos familiares? [...]. Porque muitas vezes a gente fecha os olhos e está tão evidente Que o familiar precisa conversar, precisa se abrir um pouco. Se o aluno colocar na cabeça, que tudo que ele está fazendo na área de saúde vai depender do que o familiar vai encontrar na casa dele, tudo facilita. (E I)

[... mas eu acho Que deveria ter a prática e a orientação do profissional como lidar, como fazer um grupo, como orientar essa família, mas realmente na prática, com a família mesmo, escolher um paciente, fazer um estudo daquele paciente e com a família juntamente, mas na prática. (E5)

Quanto aos enfermeiros Que estão atuando nos serviços de saúde mental, estes precisam manter-se atualizados Quanto às novas propostas de atuação frente à família.

[...] é esse um campo novo que está se abrindo, já existem enfermeiras interessadas em pesQuisar família, então eu acho Que a gente tem Que ir buscar mesmo e os alunos Que estão se formando tem Que correr atrás. (E2)

Os entrevistados apontam para a importância de a família participar do tratamento e indicam a necessidade deste conteúdo estar contemplado nas disciplinas de graduação. Revisitando a temática a partir das produções científicas dos enfermeiros pesquisadores, também se observa Que indicam Que trabalhar com a família tem de ser um exercício prático, pois cada uma tem sua forma singular de lidar com as situações Que estão pautadas na sua organização, crenças e na interação com o meio social ${ }^{(3)}$.

Para ampliar as formas de atuação, é importante destacar Que "aprender sobre a família" implica buscar informações em outras áreas do conhecimento e promover um diálogo constante com os profissionais que atuam nos serviços de saúde ${ }^{(9,10)}$.

\section{CONSIDERAÇÕES FINAIS}

Esta investigação buscou conhecer como os enfermeiros Que atuam em saúde mental obtiveram os conhecimentos durante a graduação e pós-graduação, como visualizam a família no cenário de cuidado e euais as contribuições para a formação dos futuros profissionais de enfermagem.

Durante a graduação, os enfermeiros obtiveram poucas informações sobre a família, fato decorrente de como a formação acadêmica está pautada no modelo biologicista onde há uma valorização do Quadro clínico em detrimento dos aspectos psicossociais envolvidos no cuidado.

No cenário do cuidado, a família é valorizada, pois depende dessa previdência a possibilidade de uma nova forma de atender o portador de sofrimento psíquico.

Os enfermeiros não desenvolvem atividades regulares com a família, mas compartilham com a equipe multiprofissional as informações Que obtêm das orientações e visitas domiciliares. Indicam a necessidade de inclusão da temática nos cursos de graduação e apontam para a necessidade de atividades práticas Que possibilitem conhecer a família enquanto um sujeito com sua intencionalidade própria.

A família no cenário de saúde mental tem um papel privilegiado nas transformações socioculturais e seria de grande valia Que os cursos de graduação contemplassem esta temática nos conteúdos programáticos, possibilitando Que o tema ao ser estudado tenha um caráter interdisciplinar.

\section{REFERÊNCIAS}

1. Senado Federal (BR). Constituição da República Federativa do Brasil. Brasília: Senado Federal; 2006.

2. Ministério da Saúde (BR). Legislação em saúde mental: 1990 2004. Brasília (DF): Ministério da Saúde; 2004.

3. Mioto RCT. Do conhecimento Que temos à intervenção Que fazemos: uma reflexão sobre a atenção as famílias no âmbito das políticas sociais. In: Althoff CR, Elsen I, Nitscke RG org.
PesQuisando a família: olhares contemporâneos. Florianópolis: Papa-Livro; 2004. p. 107-14.

4. Szymanski H. A pesquisa intervenção participante com famílias de baixa renda: um projeto participativo de atenção psicoeducacional. In: Althoff CR, Elsen I, Nitscke RG org. Pesquisando a família: olhares contemporâneos. Florianópolis: Papa-Livro, 2004. p. 1115-126. 
5. Saraceno C. The concept of family strategy and its application to the family-work complex: some theoretical and methodological problems. In: Boh K, Sgritta G, Sussman MB, editors. Cross-Cultural Perspectives on Families, Work and Change. Binghamton: The Haworth Press; 1990. p. I- 18

6. Moreno V. Vivência do familiar da pessoa em sofrimento psíquico [tese]. Ribeirão Preto: Escola de Enfermagem, Universidade de São Paulo; 2000.

7. Amarante P. Saúde Mental e atenção psicossocial. Rio de Janeiro: Fiocruz; 2007.

8. Almeida Filho N. Transdisciplinaridade e o paradigma pósdisciplinar na saúde. Saúde Sociedade 2005; 14(3): 30-50.

9. Furtado JP. Equipes de referência: arranjo institucional para potencializar a colaboração entre disciplinas e profissões. Interface - Comunic, Saúde, Educ 2007; I I (2): 239-55.

10. Saupe R, Cutolo LRA, Wendhausen ALP, Benito GAV. Competência dos profissionais da saúde para o trabalho interdisciplinar. Interface - Comunic, Saúde, Educ 2005; 9(18): 52I-36.
11. Bogdan R, Biklen S. Investigação Qualitativa em educação: uma introdução à teoria e aos métodos. Porto: Porto Editora; 1994.

12. Minayo MCS. O desafio do conhecimento: Pesquisa Qualitativa em saúde. 10ª ed. São Paulo: Hucitec; 2007.

13. Santos BR, Moraes E, Piccinini G, Sagebin H, Eidt O. Formando o enfermeiro para o cuidado à saúde da família: um olhar sobre o ensino de graduação. Rev Bras Enferm 2000; 53(esp): 49-59.

14. Olschowsky A. O ensino de enfermagem psiQuiátrica e saúde mental: análise da pós-graduação "lato sensu" [tese]. São Paulo: Escola de Enfermagem, Universidade de São Paulo; 2001

15. Campos PHF, Soares CB. Representação da sobrecarga familiar e adesão aos serviços alternativos em saúde mental. Psicol Rev 2005; I I (18): 219-37.

16. Cavalheri SC. Transformações do modelo assistencial em saúde mental e seu impacto na família. Rev Bras Enferm 20 10 ; 63(1): $51-57$ 